\title{
Paraplegia
}

\section{Systematic Lower Limb Phlebography in Acute Spinal Cord Injury in 147 Patients}

\author{
A. Yelnik. MD, ${ }^{1}$ O. Dizien, $M D,{ }^{1}$ B. Bussel, $M D,{ }^{1}$ E. Schouman-Claeys, $M D,{ }^{2}$ \\ G. Frija, MD, ${ }^{2}$ S. Pannier, MD, ${ }^{1}$ J. P. Held, $\mathbf{M D}^{1}$ \\ ${ }^{\prime}$ Service de Rééducation Neurologique, ${ }^{2}$ Service de Radiologie, Hôpital Raymond \\ Poincaré, 92380 Garches, France.
}

\begin{abstract}
Summary
This study was concluded on paraplegic and tetraplegic patients of all aetiologies except neoplasic, where paralysis developed within 48 hours. All patients were admitted to the rehabilitation department within 90 days after the onset of paralysis. In a preliminary review of 328 files, there were 27 cases of clinical deep vein thrombosis (DVT) and 10 with pulmonary embolism (PE), 6 of which were fatal. A prospective study was conducted, based on systematic detection of asymptomatic DVT with phlebography. Among the 147 patients, 20 previously presented with DVT. The 127 others underwent phlebography which showed 39 DVT in 29 patients. Eighty seven patients with negative phlebography underwent a second study a month later which showed 14 DVT in 12 patients. Only one minor pulmonary embolism occurred in these 147 patients. The incidence of DVT after acute spinal cord injury and the frequent absence of clinical manifestations were confirmed. Prophylactic anticoagulant therapy is useful but insufficient. This study demonstrates that systematic and repeated detection of DVT by phlebography may reduce the incidence of $P E$.
\end{abstract}

Key words: Acute Spinal Cord Injury; Paraplegia; Pulmonary embolism; Deep venous thrombosis; Phlebography.

Pulmonary embolism (PE) is one of the leading causes of death after acute spinal cord injury (SCI) (Stover 1987). The incidence of deep venous thrombosis (DVT) ranges from 15 to $90 \%$ according to different investigators (Bors, 1954; Silver, 1970; Brach, 1977). These discrepancies depend on the way diagnosis is made and on the duration of the spinal cord lesion. The efficacy of preventive anticoagulant therapy as observed by many investigators appears real but results are inconclusive 
(Hachen, 1974; Silver, 1974; Perkash, 1978; Watson, 1978; El Masri, 1981). Some investigators believe it is not useful at all (Merli, 1988).

The aim of this study was to determine the causes responsible for the high incidence of PE despite preventive anticoagulant therapy in a rehabilitation department. Indeed, in a preliminary retrospective study we conducted in 328 consecutive recent paraplegic patients (using the same criteria as those of the prospective study), the incidence of clinically-diagnosed DVT confirmed with phlebography, was $53 \%(11 / 21)$ in patients who did not receive preventive anticoagulant therapy and $9 \%(26 / 307)$ in those who were given low doses of calcium heparin $(5000 \mathrm{UI} \times 3)$. Ten cases of PE occurred, 6 of which were fatal in patients receiving preventive anticoagulant therapy. Then we may assume that many patients have a DVT before being admitted to the rehabilitation department and that these DVT are often asymptomatic. They might have developed at a very early stage (Brach, 1977) before initiation of preventive anticoagulant therapy or in spite of it.

A prospective study was conducted, based on a systematic phlebographic DVT investigation in order to: (1) Estimate the high incidence of DVT after acute SCI; (2) Demonstrate whether or not preventive therapy of non-symptomatic DVT reduces the incidence of clinical pulmonary embolism; (3) Identify the high risk DVT patient, and (4) Determine the duration of the highest risk period.

\section{Patients and methods}

Inclusion criteria:

-Paraplegic and tetraplegic patients; all aetiologies except for neoplasms.

-Paralysis occurring within 48 hours of SCI.

-Admission to the rehabilitation department within 90 days after the onset of paraplegia.

Clinical follow-up covered the entire hospital stay, meaning an average of 6 months for paraplegics and 13 months for tetraplegics.

\section{Patients}

This study was carried out between January 1986 and may 1988. Out of 150 patients included, only 147 were studied; 3 were excluded because of the poor quality of their phlebography (Table I). There were 41 females and 106 males, the mean age was $34.5 \pm 15.5$ years; in 25 cases the aetiology was not traumatic (infarct, benign tumour, etc); the upper level of the spinal cord lesion involved the cervical spine in 48 patients, the thoracic spine in 78 and the lumbar spine in 21 others. The average time between onset of paraplegia and admission to the Rehabilitation Department was 42 days.

\section{Methods}

A phlebography (PHL1) of both lower limbs was performed between the first and the seventh day (mean:5 days) following admission to the department. PHL1 was carried out by injecting $60 \mathrm{ml}$ of ioglaxate (Hexabrix) into a superficial vein on the dorsum of each foot. No patient presented any contraindication to PHLl i.e. 
Table I Clinical course of DVT in selected patients

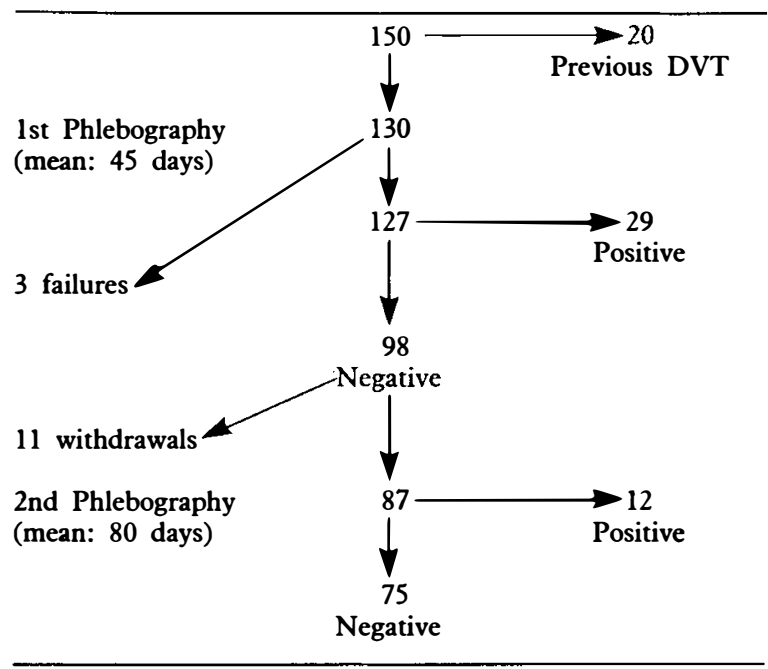

allergy to iodine, skin lesions of the dorsal aspect of the foot and serum creatinine levels above $200 \mathrm{micromol} / \mathrm{l}$.

Twenty patients who developed DVT (including $6 \mathrm{PE}$ ) between the onset of paraplegia and their admission to the department did not undergo PHL1. Data of these patients were used to evaluate risk factors. Among the 127 others, 115 were receiving preventive anticoagulant therapy (either low-doses of calcium heparin, low molecular weight heparin or oral anticoagulation) instituted within a few days after onset of paraplegia. When the PHLl was normal, it was maintained by administering low doses of calcium heparin $(5000 \mathrm{u} \times 3)$ or a low molecular weight heparin (Fraxiparine $0.3 \mathrm{ml} \times 1$ ). A second phlebography (PHL2) was performed a month later (ranges from 30-38 days, mean: 35 ). All patients with confirmed DVT received standard curative anticoagulant therapy.

During the interval between the two PHL's, daily clinical examinations and weekly laboratory tests (red blood cell count, haemoglobin, platelet count), were performed. Clinical suspicion of DVT had to be confirmed by phlebography, which superseded PHL2.

Possible risk factors were analysed in the 147 patients at the time of the DVT or at PHL1. The level of paraplegia was defined by the upper limit of the lesion, which is the highest metamer exhibiting paralysis. Each paraplegic patient was classified in one of the following categories: $0=$ complete; $1=$ incomplete. Spasticity, or rather, spinal automatism, was divided into 2 categories: without (0) or with (1) spontaneous or provoked spasms.

\section{Results}

The incidence of DVT at the time of PHLl is reported in Table II. DVT was detected in 29 patients, and was bilateral in 10, in the first 127 PHLs. In addition to the 20 previous cases of DVT, 49 out of 147 patients developed a DVT on average 45 days after the onset of paraplegia. 
Table II Incidence of DVT (DVT $=1)$ on average 45 days after the onset of paraplegia according to preventive anticoagulant therapy

\begin{tabular}{lccccc}
\hline & $\begin{array}{c}\text { DVT=1 } \\
\text { Before } \\
\text { admission }\end{array}$ & $\begin{array}{c}\text { At } \\
\text { admission }\end{array}$ & Total & DVT=0 & Total \\
\hline $\begin{array}{l}\text { No treatment } \\
\text { Low doses of calcium } \\
\quad \text { heparin }\end{array}$ & 6 & 5 & $11(55 \%)$ & 9 & 20 \\
$\begin{array}{l}\text { Low molecular weight } \\
\text { heparin }\end{array}$ & 13 & 13 & $26(29 \%)$ & 63 & 89 \\
$\begin{array}{l}\text { Oral anticoagulants } \\
\text { (1) }\end{array}$ & 1 & 6 & $7(41 \%)$ & 10 & 17 \\
& 20 & 5 & $5(24 \%)$ & 16 & 21 \\
\end{tabular}

Only one minor PE occurred in one patient 2 weeks after PHL1 was negative. PHLl revealed a thrombus in the right posterior tibial vein.

A second phlebography (PHL2) was possible in only 87 patients out of the 98 with normal PHL1. PHL2 involved the patient who had clinical PE and 2 patients in whom PHL2 were performed a few days before the thirtieth day because DVT was clinically manifest. DVT was observed in 12 patients, with bilateral involvement in 2 (Table III).

The efficacy of preventive therapy using low doses of calcium heparin is shown in Table II $(\mathrm{p}<0.05)$. The efficacy of low molecular weight heparin (Fraxiparine) did not appear to be significantly different from calcium heparin in an initial assessment (Tables II and III). The number of cases of haemorrhage was the same regardless of treatment. No patient had thrombocytopenia.

The site of the thrombus is indicated in Table IV. In PHL1, 11 thrombus in the 39 were in a femoral or an iliac vein. In PHL2, 14 DVT's were located in the calf except for one which was popliteal. In the 41 patients with a DVT, there were clinical manifestations in only 9 cases, 8 of which were related to a thrombus in a calf vein and once in a femoral vein. Only 1 patient out of the 11 who developed a thrombus above the knee showed clinical signs.

Risk factors for DVT during the 45 days after the onset of paraplegia are reported in Table V. DVT was significantly more frequent in males than in females. None of the other factors is statistically significant, but the frequency of DVT seems higher in case of traumatic aetiology or when paralysis is complete. Between the forty-fifth and the eightieth day, among the 87 patients who underwent PHL2, none of these factors is significantly related DVT. Nevertheless,

Table III Incidence of DVT (DVT $=1)$ on average 80 days after the onset of paraplegia in 87 patients who underwent a second phlebogram 1 month after an initial one was normal, according to preventive anticoagulant therapy

\begin{tabular}{lccc}
\hline & DVT $=1$ & DVT=0 & Total \\
$\begin{array}{l}\text { No treatment } \\
\text { Low doses of }\end{array} \quad$ calcium heparin & 1 & 1 & 2 \\
Low molecular weight & 6 & 27 & 33 \\
$\quad$ heparin & 5 & 45 & 50 \\
Oral anticoagulants & 0 & 2 & 2 \\
& 12 & 75 & 87 \\
\hline
\end{tabular}


Table IV Upper limit of thrombus detected by: First phlebography (PHL 1) in 29 of 127 patients 45 days after the onset of paraplegia and a second phlebography (PHL 2) in 12 of 87 patients 80 days after the onset of paraplegia

\begin{tabular}{lccccc}
\hline & PHL & \multicolumn{2}{c}{ PHL 2 } \\
& Right & Left & Right & Left \\
\hline Calf & 11 & 16 & 7 & 6 \\
Popliteal vein & 1 & 0 & 0 & 1 \\
Superficial femoral vein & 5 & 4 & 0 & 0 \\
Deep femoral vein & 1 & 0 & 0 & 0 \\
Iliac vein & 0 & 1 & 0 & 0 \\
Inferior vena cava & 0 & 0 & 0 & 0 \\
Total & 18 & 21 & 7 & 7 \\
\hline
\end{tabular}

Table V Presence of deep venous thrombosis (DVT) according to clinical parameters on admission to the department (mean 45 days)

\begin{tabular}{cccc}
\hline & DVT $=1$ & DVT $=0$ & Total \\
Mean age & $38 \cdot 4$ & $33 \cdot 9$ & $34 \cdot 5 \pm 15 \cdot 5$ \\
Sex Female & $7(17 \%)^{*}$ & 34 & 41 \\
$\quad$ Male & $42(39 \cdot 6 \%)$ & 64 & 106 \\
Obesity + & $6(46 \%)$ & 7 & 13 \\
$\quad-$ & $43(32 \%)$ & 91 & 134 \\
Aetiology: Traumatic & $45(36 \cdot 9 \%)$ & 77 & 122 \\
Other & $4(16 \%)$ & 21 & 48 \\
Level C1-C7 & 15 & 33 & 18 \\
T1-T5 & 7 & 11 & 26 \\
T6-T9 & 8 & 18 & 34 \\
T10-T12 & 13 & 21 & 21 \\
L1-L5 & 6 & 15 & 35 \\
Surgery + & $38(33 \cdot 9 \%)$ & 74 & 50 \\
Concomitant trauma & $11(31 \cdot 4 \%)$ & 24 & 72 \\
Paralysis 0 & 19 & 31 & 83 \\
1 & 26 & 46 & 64 \\
Spasticity 0 & 30 & 53 & 49 \\
1 & 19 & 45 & 48 \\
\hline
\end{tabular}

${ }^{*} \mathrm{p}<0.05$

no DVT occurred among the 13 lumbar paraplegics, compared to 7 among the 30 tetraplegics.

Four haemorrhagic events were observed among patients who received therapeutic doses of anticoagulants: 1 haematuria, 2 haematoma in the thigh and 1 digestive haemorrhage revealing a gastric ulcer. Among patients undergoing preventive therapy, we observed: 1 haematuria, 1 haematoma in the thigh, 1 haemorrhage due to a decubitus ulcer and 1 unexplained anaemia.

The duration of the high risk period can be assessed by relating the incidence of DVT to the onset of paraplegia. Upon admission to the rehabilitation department, on average 45 days after the onset, 33\% of patients (49/147) presented with or previously presented DVT. Among those patients who did not have DVT by the 
forty-fifth day, $13 \cdot 8 \%$ had one by the eightieth day on average. Hence, the high risk period extends, at least, to the end of the third month.

\section{Discussion}

The existence and severity of asymptomatic DVT after acute SCI, as evidenced by 6 cases of fatal PE with no clinical manifestation of DVT, incited us to search for DVT systematically.

Our results show the incomplete efficacy of preventive anticoagulant therapy in recent onset paraplegics in a Rehabilitation Department. The high incidence of DVT in such patients and the frequent lack of clinical manifestation were confirmed. This is why DVT might have been thought to be absent (Cook, 1949). The value of systematic investigation and treatment of asymptomatic DVT appears to be confirmed by the decrease in patients with PE. Only 1 minor clinical PE occurred among 127 patients, versus 10 with PE ( 6 of which were fatal) among the 307 comparable patients analysed in the preliminary retrospective study. As far as our patient population is concerned, these results show that two PHL's are sufficient. In our opinion there is no need for a third PHL since we never observed $P E$ at a later stage.

PHL was chosen because of its reliabiity. The sensitivity of ultrasonic Doppler technique and plethysmography is insufficient (Hachen, 1974; Holden, 1981; Sandler, 1984). The use of $\mathrm{I} 125$ radiolabelled fibrinogen is a difficult technique and its sensitivity can be excessive; on the other hand, it may not detect an organised thrombus. Real time echotomography associated with the Doppler method (Luizy, 1986) still is not sensitive enough. On top of this, examining paraplegic patients in the standing position is difficult.

The main hazard of PHL is post-PHL thrombosis (Hessel, 1981), if one excludes contraindications. Its incidence is less than or equal to $0.5 \%$ with low osmolarity contrast media (Albrechtsson, 1979; Hessel, 1981). In our patients, this risk was even lower, because all patients received preventive anticoagulant therapy. This risk should be compared with the incidence of fatal PE, which is often higher than 1\% (Silver, 1970; Watson, 1978).

The only accident we noted among 214 PHL's was a mild allergic reaction at the time of the second PHL in a woman with no history of allergy.

All cases of DVT including those located in the calf were treated, because of the specific tendency of thrombi to extend and migrate (Moreno-Cabral, 1976; Maliska, 1985). However, the main problem is that more patients must be given effective anticoagulant therapy. There is indeed a higher rate of haemorrhagic complications. Fortunately these accidents were not severe. The risk of death due to massive haemorrhage is lower than that for PE.

No difference was observed in the incidence of DVT according to the side involved. The site of the thrombus appears to be related to the interval following paraplegia: on the forty-fifth day, one third of DVT involved femoral or iliac veins, on the eightieth day all cases involved the calf veins.

Oral anticoagulation as a preventive therapy given in the previous department seems more efficient, at the time of PHLl (Table II), then low doses of calcium heparin. However, these two treatments cannot be compared because the oral anticoagulation therapy was given at such doses as to induce effective anticoagula- 
tion. In our department, we do not use oral anticoagulation as preventive therapy because of the haemorrhagic risks. The efficacy of low doses of calcium heparin versus a low molecular weight heparin between PHL1 and PHL2 seems to be the same. Nevertheless the two groups were not strictly randomised.

It has not been possible to identify a profile for an average high-risk paraplegic. In fact, unanimously-accepted risk factors (age, obesity ...) (Kakkar, 1970; Miller, 1983) were insufficiently predicative for our population. Moreover, some factors which are more specific of paraplegics seem to be unimportant: spinal surgery, level of the paraplegia and existence of spasms. The length of preventive treatment after acute SCI cannot be ascertained. The incidence of DVT is higher during the first 45 days (49/147) than in the following 35 days (12/87). The risk still exceeds $13 \%$ during the third month.

\section{Conclusion}

We have confirmed the high incidence of DVT in recent onset cases of paraplegia and the frequent absence of clinical manifestations.

Preventive anticoagulant therapy with low doses of heparin or low molecular weight heparin is useful but insufficient.

We have shown that systematic and repeated detection of asymptomatic DVT by PHL may reduce the incidence of PE.

We believe that preventive anticoagulant therapy must be maintained for at least 3 or 4 months in patients with SCI.

\section{Acknowledgements}

We are grateful to J. N. Fiessinger, MD, for his critical review of the manuscript.

\section{References}

AlBREChTSSON U, OLSSON CG 1979 Thrombosis after phlebography: a comparison of two contrast media. Cardiovascular Radiology 2:9-18.

Bors E, ConRAD CA, MASSEl TB 1954 Venous occulsion of lower extremities in paraplegic patients. Surgery, Gynaecology and Obstetrics 99:451-454.

Brach BB, Moser KM, Cedar L, MinTeer M, Convery R 1977 Venous thrombosis in acute spinal cord paralysis. Fournal of Trauma 17:(4)289-292.

CoOK A, Lyons HA 1949 Venous thromboembolic phenomena. Their absence in paraplegic and tetraplegic patients. American fournal of the Medical Sciences 218:155-159.

EL MASRI WS, SILVER JR 1981 Prophylactic anticoagulant therapy in patients with spinal cord injury. Paraplegia 19:334-342.

HACHEN HJ 1974 Anticoagulant therapy in patients with spinal cord injury. Paraplegia 12:176-187.

Hessel SJ, Adams DF, Abrams HL 1981 Complication of angiography. Radiology 138:273-281.

Holden RW, KLATTE EC, PARK HM, et al. 1981 Efficacy of non invasive modalities for diagnosis of thrombophlebitis. Radiology 141:63-66.

Kakkar VV, Howe CT, Nicolaides AN, RenNey JTG, Clarke MB 1970 Deep vein thrombosis of the leg. Is there a 'high risk' group? A merican fournal of Surgery 120:527-530.

LUIZY F, FrANCESCHI C, FranCo G 1986 A methodology of venous investigation by real time echotomography associated with directional and continuous wave Doppler. Annales de Medicine Interne 137:484-487.

Maliska P, Tiercelin G, Vallee C, Baer M, Pasteyer J 1985 Phlebographie préopératoire systématique chez les traumatisés des membres inférieurs opérés tardivement. Annals of French Anesthesia 4:23-26.

Merli GJ, Herbison G, Weitz MH, et al. 1988 Comparison of low dose heparin, low dose heparin plus Dihydroergotamine, low dose heparin plus electrical stimulation and placebo as prophylaxis for deep vein thrombosis in acute spinal cord injury. Paraplegia 26:124-125. 
Miller F, Young C, WANG GJ 1983 The incidence of thromboembolic disease. Clinical Orthopaedics and Related Research 176:210-216.

MORENO-CABRAL R, KISTNER RL, NORDYKe RA 1976 Importance of calf vein thrombophlebitis. Surgery 80:735-742.

Perkash A, Prakash V, Perkash I 1978 Experience with the management of thromboembolism in patients with spinal cord injury: Part 1, incidence, diagnosis and role of some risk factors. Paraplegia 16:322-331.

SANDLER DA, MARTIN JF, DUNCAN JS, et al. 1984 Diagnosis of deep-vein thrombosis:comparison of clinical evaluation, ultrasound, plethysmography and venoscan with X-ray venogram. Lancet ii, 716-719.

Silver JR, MOULTON A 1970 Prophylactic anticoagulant therapy against pulmonary embolism in acute paraplegia. British Medical fournal 2:338-340.

SILVER JR 1974 The prophylactic use of anticoagulant therapy in the prevention of pulmonary emboli in one hundred consecutive spinal injury patients. Paraplegia 12:188-196.

Stover SL, FINE PR 1987 The epidemiology and economics of spinal cord injury. Paraplegia 25:225-228.

WATSON N 1978 Anticoagulant therapy in the prevention of venous thrombosis and pulmonary embolism in the spinal cord injury. Paraplegia 16:265-269. 